\title{
Predictors of Time to Viral Load Suppression of Adult PLWHIV on ART in Arba Minch General Hospital: A Follow up Study
}

\author{
Sultan Hussen ${ }^{1 *}$, Mohammedaman Mama $^{2}$, Bitew Mekonnen ${ }^{3}$, Manaye \\ Yihune $^{1}$, Mulugeta Shegaze ${ }^{1}$, Negussie Boti ${ }^{1}$, Mohammed Shure ${ }^{4}$
}

\footnotetext{
OPEN ACCESS

Citation: Sultan Hussen, Mohammedaman Mama, Bitew Mekonnen, et al. Predictors of Time to Viral Load Suppression of Adult PLWHIV on ART in Arba Minch General Hospital: a Follow up Study. Ethiop J Health Sci. 2019; 29(6):751.doi:http://dx.doi.org/10.4314/ej hs.v29 i6.12

Received: June 03, 2019

Accepted: July 17, 2019

Published: November 1, 2019

Copyright: (C2019 Sultan H, et al. This is an open access article distributed under the terms of the Creative Commons Attribution License, which permits unrestricted use, distribution, and reproduction in any medium, provided the original author and source are credited.

Funding: Arba Minch University

Competing Interests: The authors declare that this manuscript was approved by all authors in its form and that no competing interest exists.

Affiliation and Correspondence:

${ }^{1}$ Arba Minch University, College of

Medicine \& Health Sciences,

Department of Public Health, Arba Minch, Ethiopia

${ }^{2}$ Madda-Walabu University, College of Medicine \& Health Sciences, Department of Laboratory, Bale Goba, Ethiopia

${ }^{3}$ Arba Minch University, College of Medicine \& Health Sciences, Department of Nursing, Arba Minch, Ethiopia

${ }^{4}$ Arba Minch University, College of Social Sciences and Humanities, Department of English Language and Literature, Arba Minch, Ethiopia

*Email: Sultanhussn@gmail.com
}

\section{ABSTRACT}

Background: Access to antiretroviral drugs for all infected persons in need is a global health priority. The viral load and CD4 counts should be monitored regularly. The plasma viral load should be reduced by as much and for as short as possible. Identifying factors that predict time to viral load suppression of patients on antiretroviral therapy regimens is thus vital to optimizing therapeutic success. Therefore, this study aimed to estimate the time to viral load suppression and identify predictors of time to viral load suppression of patients on antiretroviral therapy at Arba Minch general Hospital.

Methods: This study was observational study using data abstracted from medical records, patient interviews and laboratory work-up during 6 months of follow up. The data were collected from 152 naive to anti-retro viral drug patients. The univariable and multivariable Cox proportional hazard regression analyses were done to identify predictors.

Result: The median survival time of viral load suppression among adult patients living with HIV was 3 months with 95\% CI (2.68, 3.32). The Cox-proportional hazard analysis shows baseline CD4 count of $<200$ cells $/ \mathrm{mm}^{3}$ (AHR=0.683, CI:0.471, 0.990), baseline viral load of $<10,000$ copies/ml (AHR=4.135, CI:1.835, 9.317), having baseline Cotrimoxazole preventive therapy $(A H R=1.997$, CI:1.108, 3.600), having baseline Isoniazid preventive therapy $(A H R=3.085, C I: 1.721,5.529)$ and good adherence level to $A R T$ $(A H R=2.648, C I: 1.202,5.834)$ significantly predict the time to viral load suppression.

Conclusion: Early improvement and maintenance of CD4 count and viral load to normal level should be attained through streamlining and strengthening monitoring and counseling of patients on adherence to ART, Cotrimoxazole and Isoniazid drugs. Key Words: Human immunodeficiency virus; Viral load suppression; Arba Minch; Ethiopia

\section{INTRODUCTION}

The human immunodeficiency virus (HIV) infection continues to be one of the public health issues these days $(1,2)$. An estimated 36.7 million individuals were identified as the people living with HIV 
(PLWHIV) at the end of 2016 and 54\% of adults living with HIV are currently receiving life-long antiretroviral therapy (ART) (3). In Ethiopia, a total of 718,500 people were living with HIV/AIDS at the end of 2016 (4).

To tackle this problem, new global efforts have brought that the number of people receiving HIV treatment has increased dramatically in recent years, particularly in resource-poor countries (3). Among resource-poor countries, Ethiopia has significant success in scaling up anti-retroviral therapy services since 2005 (5).

The primary goal of initiating ART among HIV patients is to suppress the HIV replication and to restore the immune function. The clinical decision to check whether such goal has been achieved is made through periodic viral load testing and CD4 cell counting (6). The newly revised and published guidelines regarding the use of ART included the recommendation that both viral load and CD4 lymphocyte counts should be monitored regularly $(7)$.

According to different result of the studies, the median duration to suppress the viral load from the initiation of ART to suppression of the viral load below 1000 copies $/ \mathrm{ml}$ is 1 month to 7 months (8-12). The predictors of time to viral load suppression, identified by different studies, are: the choice of treatment regimen, initial viral load, baseline CD4 count and previous anti-retroviral (ARV) treatments used $(8,10)$. But, as far as our search engine, the study done on time to viral load suppression is limited in Ethiopia, particularly in Arba Minch context on patients newly initiating ARV regimens. Therefore, this study aimed to identify predictors of time to viral load suppression among adult PLWHIV who are newly started ART in Arba Minch General Hospital (AMGH).

\section{MATERIALS AND METHODS}

Study Setting, Design and Participants: A prospective follow up study was conducted among HIV-infected patients receiving ART at the AMGH from March 1, 2017 to February 28, 2018. In 2017, there are 3927 adult PLWHIV ever enrolled on first line ART (13).
The calculation of the required sample size for the number of study participants needed for this study was calculated by using free and open source statistical software for epidemiologic statistics called Open-Epi Version 3.01 based on the following assumptions: The study done in public HIV treatment settings of Haiphong, Vietnam reported that the viral load suppression rate was $77 \%$. Among those who have viral load suppression, the proportion of patients with poor adherence during ART was $62.3 \%$ and good adherence during ART was $37.7 \%$ (14). In addition, 95\% Confidence interval, $80 \%$ power and a minimum detectable alternative of $\pm 5 \%$. Under these circumstances, the calculated sample size was 146 participants. With an assumed nonresponse rate of $4 \%$, the sample size needed for this study was $146 \mathrm{X} 0.04+146=152$ participants. The study only included persons living with HIV (PLWHIV) who were newly initiated ARV drugs for the first time after March 1, 2017 and whose age was $\geq 15$ years at the start of the treatment. The participants were selected using systematic random sampling.

Data collection tools, measurements and procedure: The data collection tool was prepared based on the revised 2017 Federal Ministry of Health HIV patient card format (15), patient care follow-up formats. In addition, it was modified by using different peer reviewed published literature (8-12).

At the beginning of the data collection for the study, the data on participant's socio-demographic characteristics, baseline CD4 count, WHO clinical staging, weight and height, Tuberculosis (TB) infection status, other opportunistic infections, functional status, viral load, Cotrimoxazole preventive therapy (CPT), Isoniazid preventive therapy (IPT) and initial treatment regimen were collected. Then at the end of each month the data on CD4 count and viral load were collected.

The specimen for the laboratory tests of CD4 count and viral load were collected by the trained laboratory staff at the facility. For both tests 4-5 $\mathrm{ml}$ of whole blood was drawn from each participant using vacutainer tube separately with anticoagulant following standard veni-puncture protocols for viral load testing. Furthermore, Plasma sample was assayed for the presence of

DOI: http://dx.doi.org/10.4314/ejhs.v29i6.12 
HIV RNA using Amplicor Monitor standard assay, version 1.5 (Roche Molecular Systems).

The outcome of interest was time to viral load suppression which is the time to the first of at least five consecutive viral load measurements below 1000 copies $/ \mathrm{ml}$. Which was measured as starting time was the first day of ART initiation between March 1, 2017 to February 30, 2018, and the end time was either the participants developed viral load suppression or became censored observation. According to WHO's strategy for the surveillance and monitoring of HIV drug resistance in low and middle income countries (LMICs), a viral load of $<1000 \mathrm{RNA}$ copies $/ \mathrm{ml}$ were taken as evidence of viral load suppression.

Pre-test of the tool were conducted on PLWHIV at Sawula Hospital on $5 \%$ of the study participants to check the accuracy and consistency of the data collection tool.

Data processing and analysis: After the data were checked, coded, entered and exported to SPSS statistical software version 20, the analysis and modeling were conducted at several steps. Firstly, simple descriptive statistics such as a frequency distribution and percentages were performed to describe the characteristics of the study participants. Kaplan-Meier survival curve were used for the purpose of comparing the event experiencing times of two or more groups. Then, a univariable Cox proportional hazard model analysis was performed for each independent variables and outcome of interest to identify independent variables for further analysis in multivariable analysis.

Upon the completion of the univariable analysis, variables with $\mathrm{p}$-value of $<0.25$ were selected for the multivariable analysis. Contexts and previous studies were also considered to make a variable candidate for multivariable analysis. In order to decide whether or not a variable is significant, the p-value should be less than 0.05 as a cut point. The crude and adjusted hazard ratios together with their corresponding 95\% CI were computed and interpreted accordingly.

The letter of ethical clearance was obtained from the institutional review board (IRB) of College of
Medicine and Health Sciences of Arba Minch University. Written consent was obtained from all study participants for blood draws and interviews. The confidentiality and privacy of participants were actively protected. Participants with a high likelihood of Virologic failure prioritized for tailored individualized treatment preparation and other interventions to improve treatment outcomes in the hospital.

\section{RESULTS}

Socio-demographic characteristics: A total of 152 adult patients receiving ART treatment from March 1, 2017 to February 30, 2018 were enrolled to this study. Out of the total study participants, 24(15.8\%), 73(48.0\%), 42(27.6\%), 13(8.6\%) were found in the age groups of 15-24, 25-34, 35-44 and $\geq 45$ years respectively. The mean $( \pm \mathrm{SD})$ age at start of ART was $32.06 \pm 8.402$ years and the median (IQR) age was 30 years $(27-37.75$ years). Most of the study participants 89 (58.6\%) were male, and majority of participants were married $82(53.9 \%)$. As far as employment status concerned, 100(65.8\%) were employed. With regard to religious status, the majority of the study participants $88(57.9 \%)$ were Christian orthodox. Ninety four $(61.8 \%)$ of them had history of substance use at initiation of ART and 102 (67.1\%) disclosed their HIV status to their family members (Table 1).

Clinical characteristics: The median baseline CD4 count was 182.50 cells/ $\mathrm{mm}^{3}$ (IQR $122.50-$ 313.50 cells $/ \mathrm{mm}^{3}$ ) and the median HIV viral load was 1, 452 copies/mL (IQR 1120 - 3407.25 copies $/ \mathrm{mL}$ ). Moreover, more than half of the study participants, $82(53.9 \%)$, had CD4 count of $<200$ cells $/ \mathrm{mm}^{3}$ and most of the participants134(88.2\%) had viral load of $<10,000$ copies $/ \mathrm{mL}$ at initiation of ART. On the other hand, $55(36.8 \%)$ of the study participants were categorized as stage one of WHO staging category. Majority of participants, 114(75\%), had no history of opportunistic infection and only 11 $(7.2 \%)$ was infected with TB at initiation of ART (Table 2).

DOI: http://dx.doi.org/10.4314/ejhs.v29i6.12 
Table 1. Socio demographic characteristics of time to viral load suppression among adult PLWHIV in AMGH, 2018.

\begin{tabular}{llll}
\hline Variables & Categories & Frequency (n) & Percent (\%) \\
\hline \multirow{3}{*}{ Age (Year) } & $15-24$ & 24 & 15.8 \\
& $25-34$ & 73 & 48.0 \\
Sex & $35-44$ & 42 & 27.6 \\
\multirow{3}{*}{ Marital status } & $45+$ & 13 & 8.6 \\
& Male & 89 & 58.6 \\
& Female & 63 & 41.4 \\
Educational status & Never Married & 43 & 28.3 \\
& Married & 82 & 53.9 \\
& Divorced & 21 & 13.8 \\
\multirow{4}{*}{ Religion } & Widowed & 6 & 3.9 \\
& No education & 25 & 16.4 \\
\multirow{4}{*}{ Residence } & Primary & 53 & 34.9 \\
& Secondary & 52 & 34.2 \\
Employment status & Tertiary & 22 & 14.5 \\
& Orthodox & 88 & 57.9 \\
Substance use & Protestant & 50 & 32.9 \\
& Others* & 14 & 9.2 \\
Disclosure status & Urban & 114 & 75.0 \\
& Rural & 38 & 25.0 \\
& Yes & 100 & 65.8 \\
\hline
\end{tabular}

* Muslim, Catholic

Table 2.Clinical related characteristics of time to viral load suppression among adult PLWHIV in Arba Minch General Hospital, 2018.

\begin{tabular}{|c|c|c|c|}
\hline Variables & Categories & Frequency & Percent (\%) \\
\hline \multirow{2}{*}{ Baseline CD4 count (cells/mm ${ }^{3}$ ) } & $<200$ cells $/ \mathrm{mm}^{3}$ & 82 & 53.9 \\
\hline & $\geq 200$ cells $/ \mathrm{mm}^{3}$ & 70 & 46.1 \\
\hline \multirow{3}{*}{ Baseline viral load (copies/mL) } & $<10,000$ copies $/ \mathrm{mL}$ & 134 & 88.2 \\
\hline & $\geq 10,000$ copies $/ \mathrm{mL}$ & 18 & 11.8 \\
\hline & WHO Stage I & 55 & 36.2 \\
\hline \multirow{3}{*}{ WHO clinical stage } & WHO Stage II & 40 & 26.3 \\
\hline & WHO Stage III & 44 & 28.9 \\
\hline & WHO Stage IV & 13 & 8.6 \\
\hline \multirow{3}{*}{ Baseline weight( $\mathrm{Kg})$} & $\geq 50 \mathrm{Kg}$ & 49 & 32.2 \\
\hline & $<50 \mathrm{Kg}$ & 103 & 67.8 \\
\hline & $<18.5^{\circ}$ & 31 & 20.4 \\
\hline \multirow[t]{3}{*}{$\operatorname{Body}$ mass index $\left(\mathrm{Kg} / \mathrm{m}^{2}\right)$} & $18.5-24.9$ & 103 & 67.8 \\
\hline & $\geq 25.0$ & 18 & 11.8 \\
\hline & Working & 104 & 68.4 \\
\hline \multirow[t]{2}{*}{ Functional status } & Ambulatory & 23 & 15.1 \\
\hline & Bedridden & 25 & 16.4 \\
\hline \multirow{2}{*}{ TB at baseline } & Yes & 11 & 7.2 \\
\hline & No & 141 & 92.8 \\
\hline \multirow{2}{*}{ Other OI at baseline } & Yes & 38 & 25.0 \\
\hline & No & 114 & 75.0 \\
\hline
\end{tabular}

DOI: http://dx.doi.org/10.4314/ejhs.v29i6.12 
Treatment related characteristics: The study participants who started ART regimen of $\mathrm{ABC} / 3 \mathrm{TC} / \mathrm{NVP}$ were $9(5.9 \%), \mathrm{AZT} / 3 \mathrm{TC} / \mathrm{NVP}$ were $30(19.7 \%)$ and TDF/3TC/NVP were $113(74.3 \%)$ of the all study participants. In addition, sixty seven (44.1\%) of the study participants have good adherence level to the ARV medications. About 43(28.3\%) patients made use of Cotrimoxazole prophylaxis and 108 (71.7\%) made use of Isoniazid prophylaxis at the time of enrollment to ART care (Table 3).

Table 3.Treatment related characteristics of time to viral load suppression among adult PLWHIV in Arba Minch General Hospital, 2018.

\begin{tabular}{llll}
\hline Variables & Categories & Frequency (n) & Percent (\%) \\
\hline \multirow{2}{*}{ CPT } & Yes & 43 & 28.3 \\
& No & 109 & 71.7 \\
IPT & Yes & 108 & 71.1 \\
& No & 44 & 28.9 \\
\multirow{2}{*}{ Initial ART regimens } & ABC/3TC/NVP or EFV & 9 & 5.9 \\
& AZT/3TC/NVP or EFV & 30 & 19.7 \\
\multirow{2}{*}{ ART adherence level } & TDF/3TC/NVP or EFV & 113 & 74.3 \\
& Good & 67 & 44.1 \\
& Fair & 59 & 38.8 \\
\hline
\end{tabular}
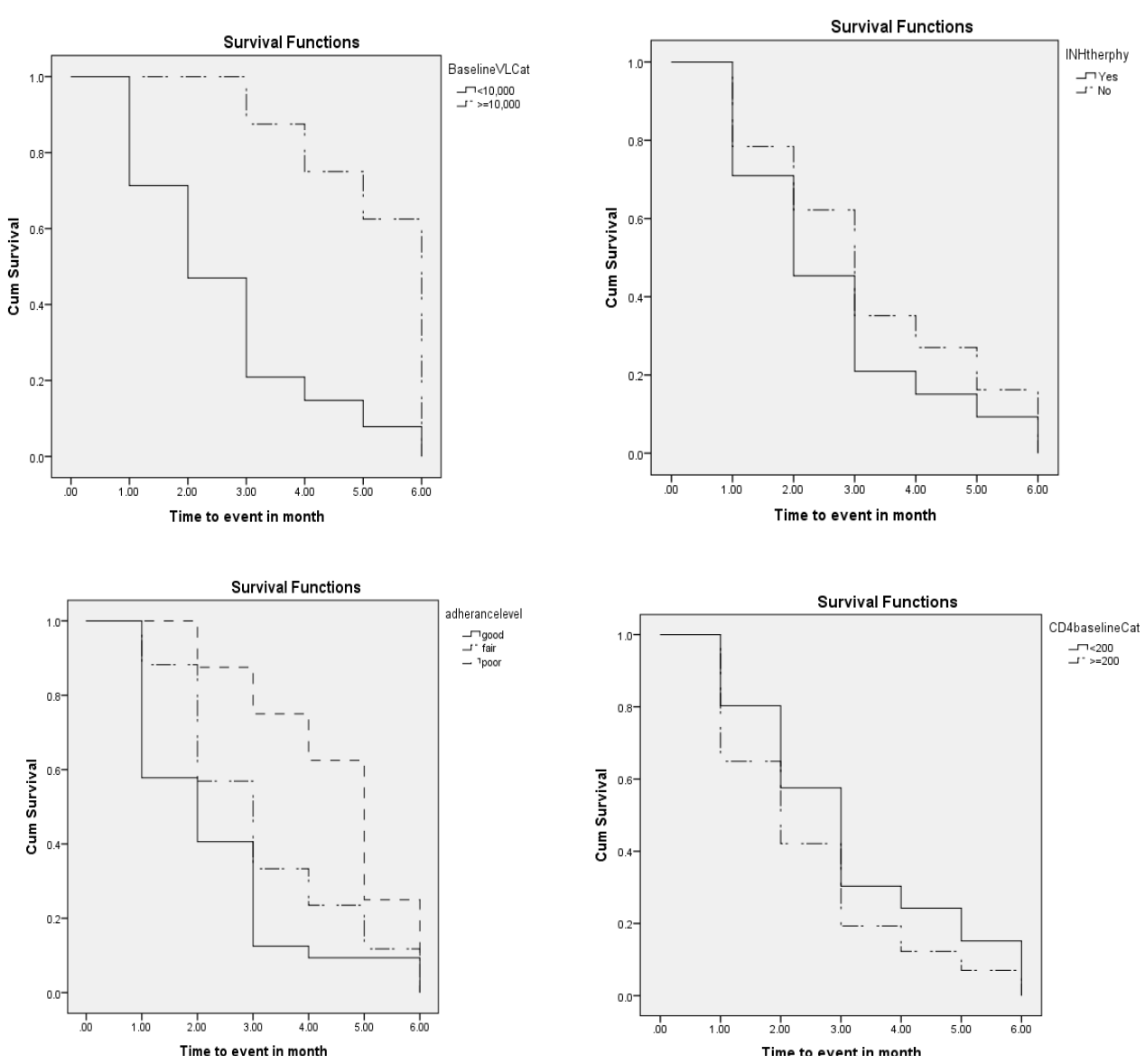

Figure 1: Kaplan-Meier estimates by Isoniazid prophylaxis, baseline viral load, adherence level and baseline CD4 count.

DOI: http://dx.doi.org/10.4314/ejhs.v29i6.12 
Status of viral load suppression: During the follow up time of the study, $123(80.9 \%)$ of participants developed the viral load suppression and $29(19.1 \%)$ participants were censored observations. The median time to viral load suppression was 3.00 months with $95 \%$ of $\mathrm{CI}$ $(2.68,3.32)$.

The KM survival curve shows that, there is a difference in time to viral load suppression among groups of baseline CD4 count, baseline viral load, baseline adherence level, employment status, disclosure status, and Isoniazid prophylaxis (Figure 1).
Predictors of time to viral load suppression: In the univariable analysis, baseline CD4 count, baseline viral load, baseline adherence level, employment status, disclosure status and Isoniazid prophylaxis are statistically significant at $25 \%$ level of significance. In addition, Cotrimoxazole prophylaxis was also included in the multivariable analysis as it is one of the very important variables in the final model. In the multivariable analysis, baseline CD4 count, baseline viral load, baseline adherence level, Cotrimoxazole prophylaxis and Isoniazid prophylaxis were statistically significant at $5 \%$ level of significant (Table 4 ).

Table 4: Predictors of time to viral load suppression among adult PLWHIV in AMGH, 2018.

\begin{tabular}{|c|c|c|c|c|c|}
\hline Co-varieties & Categories & CHR (95\% CI) & $\begin{array}{l}\text { p- } \\
\text { values }\end{array}$ & AHR (95\% CI) & $\begin{array}{l}\text { p- } \\
\text { values }\end{array}$ \\
\hline \multirow{2}{*}{$\begin{array}{l}\text { CD4 Count } \\
\left.\text { (cells/mm } / \mathbf{m m}^{3}\right)\end{array}$} & $<200$ & $0.748(0.523,1.068)$ & 0.112 & $0.683(0.471,0.990)$ & 0.044 \\
\hline & $\geq 200$ & 1 & & 1 & \\
\hline \multirow{2}{*}{$\begin{array}{l}\text { Viral Load } \\
\text { (copies/mL) }\end{array}$} & $<10,000$ & $2.561(1.233,5.320)$ & 0.012 & $4.135(1.835,9.317)$ & 0.001 \\
\hline & $\geq 10,000$ & 1 & & 1 & \\
\hline \multirow{2}{*}{$\begin{array}{l}\text { Disclosure } \\
\text { status }\end{array}$} & Yes & $1.274(0.865,1.877)$ & 0.220 & $1.166(0.775,1.754)$ & 0.460 \\
\hline & No & 1 & & & \\
\hline \multirow{2}{*}{ CPT } & Yes & $1.118(0.751,1.664)$ & 0.582 & $1.997(1.108,3.600)$ & 0.021 \\
\hline & No & 1 & & 1 & \\
\hline \multirow{2}{*}{ IPT } & Yes & $1.285(0.872,1.893)$ & 0.204 & $3.085(1.721,5.529)$ & $<0.00$ \\
\hline & No & 1 & & & \\
\hline $\begin{array}{l}\text { Employment } \\
\text { status }\end{array}$ & $\begin{array}{l}\text { Yes } \\
\text { No }\end{array}$ & $\begin{array}{l}1.363(0.927,2.005) \\
1\end{array}$ & 0.116 & $\begin{array}{l}1.349(0.893,2.036) \\
1\end{array}$ & 0.154 \\
\hline \multirow{3}{*}{$\begin{array}{l}\text { Functional } \\
\text { status }\end{array}$} & Working & $1.226(0.745,2.019)$ & 0.422 & $1.385(0.817,2.347)$ & 0.226 \\
\hline & Can walk & $1.508(0.781,2.913)$ & 0.221 & $1.510(.745,3.063)$ & 0.253 \\
\hline & Bedridden & 1 & & 1 & \\
\hline \multirow{3}{*}{$\begin{array}{lr}\text { Initial ART } \\
\text { adherence level }\end{array}$} & Good & $2.147(1.021,4.513)$ & 0.044 & $2.648(1.202,5.834)$ & 0.016 \\
\hline & Fair & $1.539(0.728,3.253)$ & 0.259 & $1.620(0.734,3.573)$ & 0.232 \\
\hline & Poor & 1 & & 1 & \\
\hline
\end{tabular}

At univariable analysis co-varieties with $\mathrm{p}<0.25$ were candidate for multivariable analysis while at multivariable analysis, covarieties with $p$-value $\leq 0.05$ were statistically significant.

\section{DISCUSSION}

This study set out to identifies the predictors of time to viral load suppression among HIV-infected adults who have newly started ART treatment in Arba Minch General Hospital. The median survival time (the expected time to viral load suppression) was 3 months with 95\% CI (2.68,

3.32). Moreover, baseline CD4 count, baseline viral load, CPT, IPT and adherence level are identified as the independent predictors of time to HIV viral load suppression.
This study depicts that the average time to viral load suppression during the study period was 3 months. The median time to viral load suppression in this study is shorter than the findings of the study in Botswana and Canadian $(9,10)$. On the contrary, it is longer than the study in the prenatal HIV/AIDS center, which needs 13.5 days to achieve viral load of less than 1000 copies/mL (8). This difference might be due to the difference in follow up period of the study participants. In fact, this study followed the participants for six months

DOI: http://dx.doi.org/10.4314/ejhs.v29i6.12 
while the participants in other studies followed for a minimum of 12 months.

The finding of this study shows that CD4 count at initiation of ART significantly affect the time to viral load suppression among study participants. The time needed for viral load suppression of those who have $\geq 200$ cells $/ \mathrm{mm}^{3} \mathrm{CD} 4$ count was shorter than those who have $<200$ cells $/ \mathrm{mm}^{3} \mathrm{CD} 4$ count. This finding corroborates the findings of the study conducted in different settings $(10,16$, 17). As can be expected, the higher CD4 counts usually correlate with low viral loads and therefore with shorter time to suppression.

This study depicts that baseline viral load is an important predictor of time to viral load suppression. Patients with low baseline viral load $(<10,000$ copies $/ \mathrm{mL})$ experienced the viral load suppression earlier than those with high baseline viral load ( $\geq 10,000$ copies $/ \mathrm{mL}$ ) which is supported by the findings from other studies $(8,10,17)$. This difference among the group might be due to the fact that the higher plasma viral load means the larger HIV reservoirs; therefore it takes longer time to achieve viral load suppression.

Furthermore, Cotrimoxazole preventive therapy has also an effect on the duration of viral load suppression. Patients with early initiation of CPT were 2 times more likely to suppress the viral load earlier than those patients who were not initiated CPT. The effect of CPT on time to viral load suppression might be due to the fact that, early initiation of Cotrimoxazole prophylaxis has a significant reduction in serious bacterial infections and mortality. Given the high underlying risk of high viral replication and serous bacterial infection during early period, this improvement in co-morbidity could correspond to a substantial success in early viral load suppression.

This study also showed that the time to viral load suppression was significantly affected by the level of patient adherence to ART. The hazard rate for those who have good adherence to ART drug were 3 fold higher to experience early viral load suppression as compared to those who have poor adherence to ART drug. As a matter of fact that adherence is the key, potentially modifiable, variable associated with time to viral load suppression (10).
The finding of this study revealed that patients with IPT at a baseline have 3 times more likely to have early viral load suppression than those without baseline IPT. The difference in time to suppression due to IPT and not having IPT might be due to HIV-positive patients with high HIV viral loads are at high risk of TB. Providing the preventive therapy in turn reduce the co-infection of TB which further reduce the duration of the viral load suppression since TB is highly associated with the depletion of CD4+ T-cell count and high viral load.

In conclusion, the overall median time to viral load suppression was 3 months with $95 \%$ CI (2.68, 3.32). This study has identified a number of controllable predictors that can lead to early viral load suppression. The low level of baseline viral load, higher level of baseline CD4 count, exposed to preventive therapies like Cotrimoxazole and Isoniazid prophylaxes and good level of adherence to ART drugs significantly affect the time to viral load suppression among adult people living with HIV.

Therefore, different stakeholders working on HIV program can maintain and potentially improve the time to viral load suppression by improving access to targeted viral load testing and CD4 count, including a routine viral load and CD4 count for all patients on ART starting from the first day of treatment. Besides, working on streamlining and strengthening adherence monitoring and counseling are also very important. Furthermore, the healthcare professional and adherent supporter should be consciously and closely follow up HIV patients and intensified targeted adherence support for those patients with poor adherence, low level of initial CD4 count and high baseline viral load.

Readers should be cautious when interpreting the findings of this study, since the data were obtained from patients in one hospital and hence the findings cannot be generalized to all PLWHIV in Ethiopia. In addition, the follow up time of six months in our study was relatively shorter compared to other studies that followed their participants for a longer period. Above and beyond, our findings are conservative.

\section{ACKNOWLEDMENTS}

We would like to acknowledge Arba Minch General Hospital administrator, health professionals and data collectors who contributed to this work. We would also like to thank all the study participants for their

DOI: http://dx.doi.org/10.4314/ejhs.v29i6.12 
participation and information they provided us. Finally, we would like to extend our gratitude to Arba Minch University for all support and opportunity provided for us to conduct this study.

\section{REFERENCES}

1. Assefa Yibeltal, Gilks CF, Lynen L, Williams O, Hill PS, Tolera T, Malvia A, Van Damme W. Performance of the Antiretroviral Treatment Program in Ethiopia, 2005-2015: strengths and weaknesses toward ending AIDS. International Journal of Infectious Diseases. 2017 Jul 1;60:70-6.

2. World Health Organization (WHO). Global Health Sector Strategy on HIV 2016-2021. Geneva, Switzerland. 2016. https://apps.who.int/iris/bitstream/handle/10665/24 6178/WHO-HIV-2016.05-eng.pdf? sequence $=1$

3. Joint United Nations Programme on HIV/AIDS (UNAIDS). Ending AIDS: Progress towards the 90-90-90 targets. Global AIDS Update. 2017. http://www.unaids.org/sites/default/files/media_ass et/Global_AIDS_update_2017_en.pdf

4. The Ethiopian Public Health Institute, HIV Related Estimates and Projections for Ethiopia 2017, The Ethiopian Public Health Institute, Ethiopia, March 2017.

https://www.ephi.gov.et/images/pictures/download 2009/HIV_estimation_and_projection_for_Ethiopi a 2017.pdf

5. Country/Regional Operational Plan (COP/ROP). Strategic Direction Summary, Ethiopia. April 21, 2017.

https://www.pepfar.gov/documents/organization/2 72012.pdf

6. The Federal HIV/AIDS Prevention and Control Office (FHAPCO). Guideline for management of opportunistic infections and antiretroviral treatment in adolescents and adults in Ethiopia. March 2008. https://www.who.int/hiv/pub/guidelines/ethiopia_a rt.pdf

7. Gazzard BG, Moyle GJ, Weber J, Johnson M, Bingham JS, Brettle R, Churchill D, Fisher M, Griffin G, Jefferies D, King E. British HIV Association guidelines for antiretroviral treatment of HIV seropositive individuals. The Lancet. 1997;349(9058):1086-92.

8. Spacek LA, Shihab HM, Kamya MR, Mwesigire D, Ronald A, Mayanja H, Moore RD, Bates M, Quinn TC. Response to antiretroviral therapy in HIV-infected patients attending a public, urban clinic in Kampala, Uganda. Clinical infectious diseases. 2006;42(2):252-9.

9. Thiébaut R, Morlat P, Jacqmin-Gadda H, Neau D, Mercié P, Dabis F, Chêne G. Clinical progression of HIV-1 infection according to the viral response during the first year of antiretroviral treatment. Aids. 2000;14(8):971-8.

10. Monforte AD, Testa L, Adorni F, Chiesa E, Bini T, Moscatelli GC, Abeli C, Rusconi S, Sollima S, Balotta C, Musicco M. Clinical outcome and predictive factors of failure of highly active antiretroviral therapy in antiretroviral-experienced patients in advanced stages of HIV-1 infection. Aids. 1998;12(13):1631-7.

11. Mocroft A, Gill MJ, Davidson W, Phillips AN. Predictors of a viral response and subsequent virological treatment failure in patients with HIV starting a protease inhibitor. Aids. 1998 12;12(16):2161-7.

12. Howard AA, Arnsten JH, Lo Y, Vlahov D, Rich JD, Schuman P, Stone VE, Smith DK, Schoenbaum EE, HER Study Group. A prospective study of adherence and viral load in a large multicenter cohort of HIV-infected women. Aids. 2002 8;16(16):2175-82.

13. Gamo-Gofa zone Health department report. Government Health Office report in 2017(unpublished).

14. Huong DT, Bannister W, Phong PT, Kirk O, Peters L. Factors associated with HIV-1 virological failure in an outpatient clinic for HIV-infected people in Haiphong, Vietnam. International journal of STD \& AIDS. 2011;22(11):659-64.

15. Ministry of Health (MOH). National guidelines for comprehensive HIV prevention, care and treatment. Addis Ababa: Ministry of Health. February 2017. https://aidsfree.usaid.gov/sites/default/files/resourc es/ethiopia_art_guidelines_2017.pdf

16. Palmer A, Gabler K, Rachlis B, Ding E, Chia J, Bacani N, Bayoumi AM, Closson K, Klein M, Cooper C, Burchell A. Viral suppression and viral rebound among young adults living with HIV in Canada. Medicine. 2018;97(22):e10562.

17. Joao EC, Gouvêa MI, Menezes JA, Sidi LC, Cruz ML, Berardo PT, Ceci L, Cardoso CA, Teixeira MD, Calvet GA, Matos HJ. Factors associated with viral load suppression in HIV-infected pregnant women in Rio de Janeiro, Brazil. International journal of STD \& AIDS. 2012 Jan; 23(1):44-7. 